\title{
PEMENUHAN HAK PASIEN ATAS INFORMASI PENYAKIT \& TINDAKAN MEDIS DALAM UPAYA MENGURANGI RISIKO TUNTUTAN PASIEN DI RUMAH SAKIT TMC TASIKMALAYA
}

\author{
Mohamad Ihsan Ramdani \\ Program Studi Magister Ilmu Hukum \\ Program Pascasarjana UNISBA \\ E-mail : hㅐsan.docsan@gmail.com
}

\begin{abstract}
Abstrak. Pasien mempunyai hak untuk mendapatkan informasi mengenai penyakit dan tindakan medis dari tenaga kesehatan di rumah sakit. Pemberian informasi ini merupakan upaya mengurangi risiko tuntutan pasien terhadap rumah sakit. Penelitian ini bertujuan untuk mengetahui pemenuhan hak pasien atas informasi penyakit dan tindakan medis di RS TMC Tasikmalaya berdasarkan Undang-Undang Nomor 44 tahun 2009 tentang Rumah Sakit, mengetahui upaya Rumah Sakit dalam mengatasi masalah-masalah yang timbul dalam pelaksanaannya dan memahami pertanggungjawaban rumah sakit yang tenaga kesehatannya tidak memberikan informasi penyakit dan tindakan medis. Penelitian bersifat deskriptif kualitatif dengan pendekatan yuridis normatif. Hasil penelitian menunjukkan bahwa pemenuhan hak pasien atas informasi penyakit dan tindakan medis di Rumah Sakit TMC Tasikmalaya secara umum sudah sesuai dengan Undang-Undang Rumah Sakit di Indonesia walaupun terdapat beberapa masalah yang masih berpotensi menimbulkan tuntutan pasien. Rumah Sakit telah berupaya mengatasi masalah-masalah yang timbul dengan mengeluarkan beberapa kebijakan dan melakukan supervisi pelaksanaan di rumah sakit. Rumah Sakit bertanggung jawab terhadap kerugian yang ditimbulkan akibat kelalaian tenaga kesehatan di rumah sakit yaitu dengan adanya doktrin respondeat superior, doktrin rumah sakit bertanggung jawab terhadap kualitas perawatan (duty of care) dan doktrin vicarious liability, hospital liability dan corporate liability. Doktrin ini diimplementasikan pada ketentuan Pasal 46 Undang-Undang Rumah Sakit di Indonesia yang menentukan bahwa rumah sakit bertanggung jawab secara hukum terhadap semua kerugian yang ditimbulkan atas kelalaian tenaga kesehatan di rumah sakit.
\end{abstract}

\section{Kata kunci : Hak Pasien, Informasi, Tanggung Jawab Rumah Sakit}

Abstract. Patients have the right to obtain information about diseases and
medical actions from health workers in the hospital. Providing this information is
an effort to reduce the risk of patients' demands on hospitals This research
purpose was to find out the fulfillment of patients' rights to disease information
and medical actions in the TMC Tasikmalaya Hospital based on Law Number 44
of 2009 concerning Hospital (Hospital Law), find out the Hospital's efforts to
overcome problems that arise in its implementation and understand the
accountability of hospitals that their health personnel do not provide disease 
information and medical action. The research is descriptive qualitative with a normative juridical approach. The results of the research indicate that the fulfillment of patients' rights to disease information and medical actions at TMC Tasikmalaya Hospital in general is in accordance with the Hospital Law even though there are some problems that still potentially lead to patient demands. The Hospital has tried to overcome the problems that have arisen by issuing several policies and conducting supervision on the hospital. Hospital is responsible for the losses caused by negligence of health workers in the hospital, namely with the existence of superior respondeat doctrine, hospital doctrine is responsible for the quality of care (duty of care) and doctrine of vicarious liability, hospital liability and corporate liability. This doctrine is implemented in the provisions of Article 46 of the Hospital Law which determines that the hospital is legally responsible for all losses incurred due to negligence of health personnel in the hospital.

\section{Keywords: Patient Rights, Information, Hospital Responsibility}

\section{A. PENDAHULUAN}

Kesadaran masyarakat akan hakhaknya dari waktu ke waktu semakin meningkat. Demikian juga hubungan pasien dengan dokter atau pasien dengan rumah sakit mengalami perubahan yang cukup berarti. Sebagai para pihak yang bermitra, maka pasien, dokter dan juga rumah sakit harus mengetahui hak dan kewajibannya masing-masing. Dalam hubungan dokter-pasien, secara relatif pasien berada dalam posisi yang lemah. Kekurangmampuan pasien untuk membela kepentingannya dalam situasi pelayanan kesehatan menyebabkan timbulnya kebutuhan untuk mempermasalahkan hak- hak pasien dalam menghadapi para profesional kesehatan. ${ }^{1}$

Dalam praktik pelayanan medis, terutama di rumah sakit nampak bahwa hubungan dokter dan pasien masih tidak seimbang, karena dokter di rumah sakit secara ilmu medis mempunyai kedudukan yang lebih unggul dan mempunyai pengetahuan di bidang kedokteran. Sementara itu, pasien berada dalam keadaan sakit, bingung, khawatir, cemas dan pada umumnya tidak mengetahui atau menguasai tentang ilmu kedokteran. Oleh karena itu, dalam konteks ini harus diusahakan adanya keseimbangan. Dokter harus memberi penjelasan (informasi) tentang tindakan medis yang akan dilakukan dan apa sebabnya. Menurut Jay

\footnotetext{
1 Danny Wiradharma, Penuntun Kuliah Hukum Kedokteran, CV Sagung Seto, Jakarta, 2010, Hlm. 51.
} 
Katz, dalam teorinya Idea of Informed Consent, mengemukakan bahwa keputusan tentang pemberian pengobatan atau perawatan kepada seorang pasien harus terjadi secara kolaboratif dan berdiskusi antara dokter dan pasiennya ${ }^{2}$. Adalah sesuatu yang keliru, jika menganggap seorang yang sakit selalu tidak boleh mengambil keputusan, karena sebenarnya pasien adalah subyek hukum yang mandiri dan dapat mengambil keputusan untuk kepentingannya sendiri. ${ }^{3}$

Undang-Undang No. 44 Tahun 2009 tentang Rumah Sakit menyebutkan, bahwa salah satu hak pasien adalah mendapat informasi yang meliputi diagnosis dan tata cara tindakan medis, tujuan tindakan medis, alternatif tindakan, risiko dan komplikasi yang mungkin terjadi, dan prognosis terhadap tindakan yang dilakukan serta perkiraan biaya pengobatan. Kejelasan informasi tentang penyakit maupun tindakan medis terkadang menjadi pokok permasalahan yang terjadi antara pasien dengan pihak

2 J.Guwandi. Informed Consent and Informed Refusal. Fakultas Kedokteran Universitas Indonesia, Jakarta, 2006, Hlm. 70.

${ }^{3}$ Chrisdiono, Pernik-Pernik Hukum Kedokteran, Melindungi Pasien dan Dokter, CV. Widya Medika, Jakarta, 2005, Hlm. 1. rumah sakit. ${ }^{4}$. Dalam hal ini pasien berhak mengetahui segala sesuatu yang berkaitan dengan keadaan penyakit, yakni tentang diagnosis, tindakan medis yang akan dilakukan, risiko dari dilakukan atau tidak dilakukannya tindakan medis tersebut.

Yang harus menjadi bahan pemikiran adalah sejauh mana batasan informasi penyakit maupun tindakan medis yang harus diberikan oleh dokter ataupun rumah sakit kepada pasiennya dan bagaimana cara penyampaian informasi tersebut sehingga tidak menimbulkan kesalahpahaman yang berakhir ke media ataupun proses pengadilan.

Rumah sakit sebagai institusi pelayanan kesehatan yang mempekerjakan dokter dan tenaga kesehatan lainnya mempunyai tanggung jawab atas segala sesuatu yang terjadi di dalamnya termasuk kerugian yang dirasakan/dialami oleh pasien maupun keluarganya. Oleh karena itu harus dipahami sejauh mana pertanggungjawaban rumah sakit secara hukum terhadap semua kerugian yang ditimbulkan atas tidak terpenuhinya hakhak pasien dan juga kelalaian yang

\footnotetext{
${ }^{4} \mathrm{http} / / /$ pantiwilasa.com/majalahkasih/detailpost/ha k-dan-kewajiban-pasien-dan-keluarga-di-rumahsakit diakses pada tanggal 5 Desember 2017 pukul 20.30 WIB
} 
dilakukan oleh dokter dan tenaga kesehatan lainnya di rumah sakit.

Berdasarkan latar belakang di atas, penulis bermaksud untuk mengetahui sejauh mana pemenuhan hak pasien atas informasi penyakit \& tindakan medis dalam upaya mengurangi risiko tuntutan pasien di Rumah Sakit TMC Tasikmalaya.

\section{Metode Penelitian}

Penelitian ini bersifat deskriptif kualitatif, yaitu berupaya mendeskripsikan obyek yang akan diteliti atau gejala-gejala secara lengkap di dalam aspek yang akan diselidiki agar lebih jelas keadaan dan kondisinya, tanpa membuat kesimpulan secara umum ${ }^{5}$ dengan metode pendekatan yuridis normatif.

Sumber data berasal dari data primer yaitu data yang diperoleh langsung dari sumber informasi dari lokasi atau subyek penelitian $^{6}$, yaitu Direktur, Kepala Bidang Pelayanan Medis, Kepala Bidang Keperawatan dan Kepala Sub Bagian Publikasi dan Informasi Rumah Sakit TMC Tasikmalaya serta data sekunder

\footnotetext{
${ }^{5}$ Soerjono Soekanto dan Sri Mammudji, Penelitian Hukum Normatif, Pengantar Singkat, Rajawali Press, Jakarta, 1990, Hlm. 14.

${ }^{6}$ Ibid Hlm. 14
}

yang diperoleh dari penelitian kepustakaan yang berupa bahan-bahan hukum. ${ }^{7}$

Teknik pengambilan data dilakukan dengan wawancara bebas maupun terpimpin dengan mengajukan pertanyaan secara tertulis yang sebelumnya telah dipersiapkan secara terstruktur pada para responden dan nara sumber dan studi kepustakaan dengan lokasi penelitian di RS TMC Tasikmalaya. Data yang telah dikumpulkan dari penelitian selanjutnya dianalisis secara deskriptif kualitatif.

\section{B. HASIL DAN PEMBAHASAN}

\section{Pemenuhan Hak Pasien Atas Informasi Penyakit dan Tindakan Medis}

Implementasi pemenuhan hak pasien atas informasi penyakit dan tindakan medis di RS TMC sudah sesuai dengan Undang-Undang No. 44 tahun 2009 tentang Rumah Sakit khususnya Pasal 32. Pasien terlebih dahulu diberikan informasi mengenai tata tertib dan peraturan yang berlaku di RS TMC Tasikmalaya melalui General Consent. Selain itu pasien juga diberikan informasi mengenai hak dan kewajiban pasien. Khusus untuk pemberian informasi penyakit dan atau

\footnotetext{
${ }^{7}$ Ibid Hlm. 14
} 
tindakan medis, pasien diberikan informasi yang meliputi diagnosis, tata cara tindakan medis, tujuan tindakan medis, alternatif tindakan, risiko dan komplikasi yang mungkin terjadi, dan prognosis terhadap tindakan. Sementara itu untuk informasi perkiraan biaya pengobatan diberikan oleh petugas billing yang dilakukan ketika mendaftar di pendaftaran rawat inap.

Berdasarkan wawancara dengan Kepala Bidang Pelayanan Medis RS TMC Tasikmalaya, dalam pelaksanaanya masih ada hambatan dan kendala yang dihadapi yaitu $:^{8}$

1. Tempat untuk penyampaian informasi masih belum memberikan kenyamanan kepada pasien dan keluarga;

2. Teknik komunikasi dan cara pemberian informasi masih belum ada keseragaman diantara para dokter maupun petugas rumah sakit yang lain.

3. Pemberian informasi mengenai penyakit dan tindakan sebagian besar diberikan dengan metode ceramah dan masih kurang menggunakan alat bantu seperti gambar ataupun leaflet.

\footnotetext{
${ }^{8}$ Wawancara dengan Kepala Bidang Pelayanan Medis RS TMC Tasikmalaya tanggal 20 Nopember 2018 di Ruang Manajemen RS TMC Tasikmalaya
}

4. Pemahaman terhadap informasi penyakit dan tindakan medis dari pasien dan keluarga masih beragam tergantung tingkat pendidikan, dan faktor sosial, ekonomi dan budaya dari pasien dan keluarga.

5. Dokumentasi sebagai bukti bahwa pasien dan keluarga sudah diberikan informasi tentang penyakit dan tindakan medis dalam rekam medis masih kurang sehingga apabila terjadi masalah masih ada kemungkinan tidak bisa menunjukan bukti bahwa informasi telah disampaikan kepada pasien dan keluarga.

6. Pemberian informasi penyakit dan tindakan medis masih banyak yang tidak dilakukan oleh DPJP utama, tapi dilakukan oleh dokter jaga ruangan ataupun petugas kesehatan yang telah didelegasikan oleh DPJP Utama.

2. Upaya-Upaya Rumah Sakit TMC Tasikmalaya Dalam Mengatasi Masalah Pemenuhan Hak Pasien Atas Informasi dan Tindakan Medis

Agar terhindar dari risiko tuntutan pasien, pelaksanaan pelayanan kesehatan di Rumah Sakit harus sesuai dengan peraturan perundang-undangan yang 
berlaku dan melakukan seluruh kegiatan rumah sakit berdasarkan Standar Prosedur yang berlaku agar tidak terjadi masalah di kemudian hari. Dalam upaya mengatasi munculnya masalah pemenuhan hak atas informasi dan tindakan medis, manajemen RS TMC Tasikmalaya telah membuat kebijakan-kebijakan yang membantu para pelaksana di lapangan baik tenaga medis maupun non medis dalam melaksanaan kegiatan pelayanannya. Berdasarkan hasil wawancara dengan Direktur RS TMC Tasikmalaya, untuk memenuhi hak pasien dalam mendapatkan informasi baik yang berkaitan dengan penyakit dan tidakan medis maupun informasi non medis telah menetapkan kebijakan yang menjadi payung hukum pelaksanaan pemberian informasi maupun edukasi di lapangan. Kebijakan pertama yang saat ini berlaku adalah kebijakan tentang Pemberian Informasi dan Edukasi di RS TMC Tasikmalaya dituangkan dalam Surat Keputusan Direktur Nomor 253/SKDIR/TMC/XII/2015 tentang Panduan Pemberian Informasi dan Edukasi Pasien di Rumah Sakit TMC Tasikmalaya. ${ }^{9}$

9 Wawancara dengan Direktur RS TMC Tasikmalaya tanggal 16 Nopember 2018 di Ruang Direksi
Dalam pemberian materi atau pesan yang akan diberikan kepada sasaran harus disesuaikan dengan kebutuhan kesehatan pasien keluarga dan masyarakat, sehingga dapat dirasakan langsung manfaatnya. ${ }^{10}$ Secara ringkas ada 6 (enam) hal yang penting diperhatikan oleh petugas RS TMC Tasikmalaya agar efektif dalam berkomunikasi dengan pasien, yaitu materi informasi apa yang disampaikan, siapa yang diberi informasi, kapan menyampaikan informasi, di mana menyampaikannya dan bagaimana menyampaikannya.

Seluruh petugas rumah sakit harus mengusahakan berkomunikasi secara dua arah dan harus mendorong agar pasien/keluarga mau dan dapat mengemukakan pikiran dan perasaannya. Petugas rumah sakit juga harus menunjukkan bahwa mereka menghargai pendapatnya, dapat memahami kecemasannya, serta mengerti perasaannya. Petugas rumah sakit dapat

\footnotetext{
10 Wawancara dengan Direktur RS TMC Tasikmalaya tanggal 16 Nopember 2018 di Ruang Direksi
} 
menggunakan pertanyaan terbuka maupun tertutup dalam usaha menggali informasi. ${ }^{11}$

Selain hal-hal di atas, petugas rumah sakit juga harus memberi penjelasan mengenai hal-hal yang menjadi perhatiannya, yang ingin diketahuinya, dan yang akan dijalani/dihadapinya agar pasien dan keluarganya tidak terjebak oleh pikirannya sendiri. Seluruh petugas rumah sakit harus berusaha untuk meluruskan persepsi yang keliru dan memberikan penjelasan mengenai penyakit, terapi, atau apapun secara jelas.

Di bagian akhir percakapan, petugas rumah sakit harus mengingatkan pasien/keluarga untuk hal-hal yang penting dan koreksi untuk persepsi yang keliru. Selain itu, petugas rumah sakit melakukan klarifikasi apakah pasien telah mengerti benar, maupun klarifikasi terhadap hal-hal yang masih belum jelas bagi kedua belah pihak serta mengulang kembali akan pesan-pesan kesehatan yang penting. ${ }^{12}$

Setiap petugas rumah sakit dalam memberikan informasi dan edukasi kepada

\footnotetext{
${ }^{11}$ Wawancara dengan Direktur RS TMC Tasikmalaya tanggal 16 Nopember 2018 di Ruang Direksi

${ }^{12}$ Wawancara dengan Direktur RS TMC Tasikmalaya tanggal 16 Nopember 2018 di Ruang Direksi
}

pasien wajib untuk mengisi formulir edukasi dan informasi, dan ditandatangani kedua belah pihak antara petugas rumah sakit dan pasien atau keluarga pasien. Hal ini dilakukan sebagai bukti bahwa pasien dan keluarga pasien sudah diberikan edukasi dan informasi yang benar.

Selain kebijakan di atas, Direktur RS TMC Tasikmalaya juga sudah mengeluarkan kebijakan lain yang berkaitan dengan hak pasien dan keluarga. Kebijakan tersebut berupa Surat Keputusan Direktur Rumah Sakit TMC Tasikmalaya No. 078/SKDIR/TMC/XII/2015 tentang Kebijakan Pelayanan Hak Pasien dan Keluarga Rumah Sakit TMC Tasikmalaya. Isi kebijakan tersebut yang berkaitan dengan pemenuhan hak pasien atas informasi penyakit dan tindakan medis adalah rumah Sakit bertanggung jawab dan mendukung hak serta kewajiban pasien dan keluarga selama dalam asuhan, memahami hak serta kewajiban pasien dan keluarga sesuai dengan undang-undang yang ditetapkan, menghormati hak serta kewajiban pasien bahwa pasien memiliki hak untuk menentukan informasi apa saja yang dapat disampaikan pada keluarga dan pihak lain dan memberikan edukasi kepada semua 
staf Rumah Sakit tentang hak dan kewajiban pasien dan keluarga beserta tanggung jawabnya.

Berdasarkan Hasil wawancara dengan Kepala Sub Bagian Publikasi dan Informasi Rumah Sakit (Humas) RS TMC Tasikmalaya, dalam kaitanya dengan pemberian informasi tentang hak pasien dan keluarga lebih khusus lagi terdapat kebijakan yaitu ${ }^{13}$ rumah sakit memberikan informasi kepada setiap pasien yang mendaftar baik pasien rawat inap maupun rawat jalan tentang hak dan kewajibannya dengan metode dan bahasa yang mudah dimengerti, menyiapkan keterangan tertulis tentang hak dan kewajiban pasien yang diberikan pada saat diterima sebagai pasien rawat jalan ataupun rawat inap, menyediakan keterangan hak dan kewajiban pasien yang dengan mudah dapat dilihat oleh publik, pemberian informasi tentang hak dan kewajiban secara tertulis diberikan sesuai usia dan bahasa pasien dan jika komunikasi tertulis dengan pasien tidak efektif dan tidak tepat maka pasien dan keluarga diberi tahu tentang hak dan kewajiban dengan bahasa yang mudah dimengerti.

\footnotetext{
${ }^{13}$ Wawancara dengan Kepala Sub Bagian Publikasi dan Informasi RS TMC Tasikmalaya tanggal 20 Nopember 2018 di Ruang Komplain
}

Untuk pemberian informasi dan persetujuan tindakan kedokteran, RS TMC Tasikmalaya telah menetapkan kebijakan mengenai pemberian informasi dan persetujuan tindakan kedokteran sebagai berikut $:^{14}$

1. Rumah Sakit menetapkan pelaksanaan pemberian informasi dan persetujuan tindakan kedokteran (informed consent) oleh Dokter Penanggung Jawab Pelayanan (DPJP) dan dapat dibantu oleh staf yang terlatih dengan bahasa yang mudah dimengerti serta sesuai dengan peraturan perundangundangan yang berlaku.

2. Rumah Sakit menetapkan setiap pasien dan keluarganya mendapatkan informasi yang terkait dengan tindakan yang memerlukan persetujuan (informed consent) sebelum dilakukan prosedur atau tindakan tertentu yang berisiko tinggi serta pasien dankeluarga dapat memberikan/menolak persetujuan tersebut.

3. Pemberian informasi dan persetujuan tindakan kedokteran dilakukan

\footnotetext{
${ }^{14}$ Wawancara dengan Kepala Bidang Pelayanan Medis RS TMC Tasikmalaya tanggal 20 Nopember 2018 di Ruang Manajemen RS TMC Tasikmalaya
} 
sebelum operasi, anaestesi (termasuk sedasi), pemakaian produk darah, tindakan dan prosedur serta pengobatan lain dengan risiko tinggi.

4. Identitas DPJP dan staf yang membantu memberikan informasi kepada pasien dan keluarga dicatat dalam rekam medis pasien.

Berdasarkan wawancara dengan Kepala Bidang Keperawatan, ketika pasien sudah masuk rawat inap, dilakukan orientasi pasien baru terebih dahulu oleh perawat di ruang rawat inap. Ketika orientasi ini, pasien juga diberikan informasi mengenai hak dan kewajiban pasien apabila pasien merasa belum terlalu memahaminya. Informasi lain yang diberikan adalah informasi mengenai alur keluhan atau complain dari pasien/keluarga untuk mengadukan kepada perawat atau bagian Humas. ${ }^{15}$ Setelah dilakukan asesmen medis awal, kemudian doker jaga ruangan melakukan konsultasi melalui telepon dengan dokter spesialis yang bertindak sebagai DPJP Utama untuk meminta advis dan rencana asuhan pasien tersebut dan barulah diberikan informasi maupun edukasi tentang penyakit pasien.

\footnotetext{
${ }^{15}$ Wawancara dengan Kepala Bidang Keperawatan RS TMC Tasikmalaya tanggal 26 Nopember 2018 di Ruang NS 6A
}

Pada saat visit di waktu berikutnya, dokter spesialis terkadang tidak memberikan informasi lagi karena sudah dilakukan oleh dokter jaga ruangan kecuali menemukan hal baru yang belum ditemukan ketika dilakukan asesmen awal. ${ }^{16}$

\section{Pertanggungjawaban Rumah Sakit} Apabila Dokternya Tidak Memberikan Informasi Penyakit dan Tindakan Medis kepada Pasien

Adanya ketentuan dalam UU No. 44 tahun 2009 tentang Rumah Sakit, yang mengatur bahwa rumah sakit akan bertanggung jawab secara hukum terhadap kelalaian tenaga kesehatan, maka menurut penulis sangat wajar bila terjadi kelalaian dalam pemenuhan hak pasien yang pada akhirnya merugikan pasien akan menjadi tanggung jawab rumah sakit. Pihak rumah sakit sebagai pengelola pelayanan kesehatan masyarakat, dan berkewajiban untuk melindungi pasien dan masyarakat serta melindungi sumber daya di rumah sakit, maka sesuai dengan ketentuan Pasal 46 UU Rumah Sakit, maka Rumah Sakit

\footnotetext{
16 Wawancara dengan Kepala Bidang Pelayanan Medis RS TMC Tasikmalaya tanggal 20 Nopember 2018 di Ruang Manajemen RS TMC Tasikmalaya
} 
dinyatakan sebagai pihak yang bertanggung jawab secara hukum. ${ }^{17}$

Kelalaian tenaga kesehatan dipertanggungjawabkan pihak rumah sakit jika tenaga kesehatan tersebut merupakan tenaga kerja dari rumah sakit tersebut. Rumah sakit bertanggung jawab atas kelalaian tenaga kesehatan, hal ini sesuai dengan ketentuan Pasal 1367 ayat (3) KUHPerdata, "bahwa majikan-majikan dan mereka yang mengangkat orang lain untuk urusan-urusan mereka adalah bertanggungjawab tentang kerugian yang diterbitkan oleh pelayan-pelayan atau bawahan mereka dalam melakukan pekerjaan untuk mana orang-orang itu dipakainya.

Dalam doktrin respondeat superior mengandung makna bahwa majikan bertanggung jawab atas tindakan-tindakan pelayan-pelayannya yang menjadi tanggung jawabnya termasuk kelalaian yang menyebabkan kerugian bagi orang lain. Selain itu dengan doktrin ini, secara hukum dan keadilan menghendaki akan

\footnotetext{
${ }^{17}$ Setya Wahyudi, Tanggung Jawab Rumah Sakit Terhadap Ketugian Akibat Tenaga Kesehatan dan Implikasinya, Jurnal Dinamika Hukum, Volume 11 No. 3 September 2011, Hlm.516
}

sikap kehati-hatian dari tenaga kesehatan. $^{18}$

Rumah sakit juga bertanggung jawab atas tindakan kelalaian yang dilakukan oleh tenaga kesehatan dengan dasar asas vicarious liability, dan bertanggung jawab terhadap kualitas perawatan (duty of care). Dalam hal tidak terpenuhinya hak pasien atas informasi penyakit dan tindakan medis oleh rumah sakit, pertanggungjawaban rumah sakit tergantung dari kerugian yang diderita oleh pasien atas kelalaian rumah sakit maupun dokter dan tenaga kesehatan lain di dalamnya.

Dalam hal pertanggungjawaban rumah sakit dalam hukum administrasi, impilkasi hukum administrasi dalam hubungan hukum antara rumah sakit dengan pasien adalah, menyangkut kebijakan-kebijakan (policy) atau ketentuan-ketentuan yang merupakan syarat administrasi pelayanan kesehatan yang harus dipenuhi dalam rangka penyelenggaraan pelayanan kesehatan yang bermutu. Kebijakan atau ketentuan hukum administrasi tersebut mengatur bagaimana tata cara

\footnotetext{
${ }^{18}$ Syahrul Machmud, Penegakan Hukum dan Perlindungan Bagi Dokter yang diduga Melakukan Medikal Malpraktek, CV. Mandar Maju, Bandung, 2012, Hlm. 105
} 
penyelenggaraan pelayanan kesehatan yang layak dan pantas sesuai dengan standar pelayanan rumah sakit, standar operasional dan standar profesi.

Dalam hal tanggungjawab rumah sakit dalam hukum perdata, rumah sakit sebagai badan hukum bertanggung jawab sebagai suatu entity (korporasi) dan juga bertanggungjawab atas tindakan orangorang yang bekerja didalamnya (respondeat superior) sebagaimana diatur dalam pasal 1365-1367 KUHP Perdata. Tanggung-jawab ini tidak hanya untuk medical/professional liability, melainkan juga untuk public liability-nya.

Selain bertanggung jawab sebagai akibat dari respondeat superior atau vicarious liability di atas, rumah sakit juga bertanggung jawab sendiri atas kerugian yang diakibatkan oleh kebijakan, peraturan dan fasilitas rumah sakit. Tanggung jawab ini tidak hanya terbatas kepada tanggung jawab di bidang medikolegal, melainkan juga dibidang public liability. Dalam hukum pidana, rumah sakit dapat juga dituntut pidana. Implikasi hukum pidana hubungan hukum rumah sakit dan pasien dalam penyelenggaraan pelayanan kesehatan adalah adanya perbuatan melanggar hukum yang dilakukan oleh pihak rumah sakit yang memenuhi unsurunsur perbuatan pidana sebagaimana diatur dalam ketentuan-ketentuan pidana.

\section{PENUTUP}

\section{Kesimpulan}

Pemenuhan hak pasien atas informasi tentang penyakit dan tindakan medis di RS TMC Tasikmalaya secara umum sudah dilakukan sesuai dengan Undang-Undang No. 44 tahun 2009 tentang Rumah Sakit, walaupun dalam pelaksanaannya masih ditemukan kendala baik yang berasal dari dokter, rumah sakit maupun dari pasien dan keluarganya yang masih memungkinkan munculnya risiko tuntutan dari pasien dan keluarganya.

Dalam upaya mengurangi risiko tuntutan dan mengatasi masalah-masalah yang timbul dalam implementasi pemenuhan hak pasien atas informasi tentang penyakit dan tindakan medis, Rumah Sakit TMC Tasikmalaya telah membuat kebijakan berupa dikeluarkannya Surat Keputusan Direktur tentang Panduan Pemberian Informasi dan Edukasi Pasien di Rumah Sakit TMC Tasikmalaya dan Kebijakan tentang Pelayanan Hak Pasien dan Keluarga serta melakukan supervisi 
pelaksanaan pemberian informasi tersebut dengan cara membuat formulir yang dijadikan bukti bahwa informasi tentang penyakit dan tindakan medis sudah disampaikan oleh dokter ataupun tenaga kesehatan yang bekerja di RS TMC Tasikmalaya kepada pasien ataupun keluarganya

Rumah sakit bertanggungjawab terhadap kerugian yang diderita oleh pasien sebagai akibat tidak diberikannya informasi tentang penyakit dan tindakan medis oleh dokter, karena secara (a) yuridis normatif merupakan penerapan ketentuan Pasal 1367 KUHPerdata dan Pasal 46 UU No. 44 tahun 2009 tentang Rumah Sakit dan secara (b) yuridis doktrinal rumah sakit bertanggung jawab atas kelalaian tenaga kesehatan dengan adanya doctrine respondeat superior dan rumah sakit bertanggung jawab terhadap kualitas perawatan (duty of care) serta (c) secara yuridis teoritis, rumah sakit sebagai korporasi berlaku asas vicarious liability, hospital liability, corporate liability, sehingga rumah sakit dapat bertanggung gugat atas kesalahan yang dibuat oleh tenaga kesehatan yang bekerja dalam kedudukan sub-ordinate (employee).

\section{Saran}

Manajemen rumah sakit harus membuat kebijakan tentang upaya pemenuhan hak-hak pasien dan berupaya untuk memenuhinya agar pasien merasa puas dan mengurangi risiko tuntutan pasien dan keluarganya ke rumah sakit. Untuk mengurangi pertanggungjawaban rumah sakit karena terjadinya segala sesuatu yang tidak diinginkan, manajemen rumah sakit harus melakukan pengawasan terhadap seluruh tenaga kesehatan yang bekerja di rumah sakit. Selain itu perlu adanya sosialisasi masalah hukum yang berkaitan dengan pelayanan kesehatan kepada seluruh civitas hospitalia.

\section{DAFTAR PUSTAKA}

\section{Sumber Buku}

Chrisdiono, Pernik-Pernik Hukum Kedokteran, Melindungi Pasien dan Dokter, CV Widya Medika, Jakarta,2005.

Danny Wiradharma, Penuntun Kuliah Hukum Kedokteran,CV Sagung Seto, Jakarta,2010.

J.Guwandi. Informed Consent and Informed Refusal. Fakultas Kedokteran Universitas Indonesia, Jakarta, 2006, Hlm. 70. 
Soerjono Soekanto dan Sri Mammudji, Penelitian Hukum

Normatif, Pengantar Singkat, Rajawali Press, Jakarta, 1990.

Syahrul Machmud, Penegakan Hukum dan Perlindungan Bagi Dokter yang diduga Melakukan Medikal Malpraktek, CV. Mandar Maju, Bandung, 2012

\section{Jurnal}

Setya Wahyudi, Tanggung Jawab Rumah Sakit Terhadap Ketugian Akibat Tenaga Kesehatan dan Implikasinya, Jurnal Dinamika Hukum, Volume 11 No. 3 September 2011

\section{Sumber Internet}

http://pantiwilasa.com/majalahkasih/detail post/hak-dan-kewajiban-pasiendan-keluarga-di-rumah-sakit diakses pada tanggal 5 Desember 2017 pukul 19.58 WIB

\section{Peraturan Perundang- Undangan}

Kitab Undang-Undang Hukum

Pidana(KUHP)

Kitab Undang-Undang Hukum Perdata

(KUHPerdata)

Undang-Undang Nomor 44 Tahun 2009

tentang Rumah Sakit 